\title{
Public Awareness, Individual Prevention Practice, and Psychological Effect at the Beginning of the COVID-19 Outbreak in China
}

\author{
Bingfeng Han ${ }^{1, *}$, Tianshuo Zhao ${ }^{1, *}$, Bei Liu ${ }^{3, *}$, Hanyu Liu ${ }^{1, *}$, Hui Zheng ${ }^{1,2}$, \\ Yongmei Wan ${ }^{2}$, Jiayi Qiu ${ }^{1}$, Hui Zhuang ${ }^{4}$, and Fuqiang $\mathrm{Cui}^{3}$ \\ ${ }^{1}$ Department of Epidemiology and Biostatistics, School of Public Health, Peking University, Beijing, China \\ ${ }^{2}$ National Immunization Program, Chinese Center for Disease Control and Prevention, Beijing, China \\ ${ }^{3}$ Department of Laboratorial Science and Technology, School of Public Health, Peking University, Beijing, China \\ ${ }^{4}$ Department of Microbiology and Center of Infectious Diseases, School of Basic Medical Sciences, Peking University, Beijing, China
}

Received April 16, 2020; accepted July 14, 2020; released online August 22, 2020

\begin{abstract}
Background: The COVID-19 has spread to more than 200 countries and territories. But less is known about the knowledge, protection behavior and anxiety regarding the outbreak among the general population.

Methods: A cross-sectional, population-based online survey was conducted in China and abroad from January 28 to February 1 , 2020. Socio-demographic information was collected and knowledge scores, practice scores, anxiety scores and perceived risk were calculated. General linear model and binary logistic regression were used to identify possible associations.

Results: We included 9,764 individuals in this study, and $156(1.6 \%)$ were from Hubei Province. The average knowledge score was 4.7 (standard deviation, 1.0) (scored on a 6-point scale); 96.1\% maintained hand hygiene, and 90.3\% of participants had varying levels of anxiety. People in Hubei Province were the most anxious, followed by those in Beijing and Shanghai. People who had experienced risk behaviors did not pay more attention to wearing masks and hand hygiene.

Conclusions: The public had high awareness on knowledge of COVID-19 outbreak, and a high proportion of people practiced good hand hygiene behavior. Many people claimed anxiety, especially in heavily affected areas during pandemic, suggesting the importance of closing the gap between risk awareness and good practice and conduct psychological counseling to public and patients.
\end{abstract}

Key words: COVID-19; awareness; prevention practice; psychology

Copyright $\odot 2020$ Bingfeng Han et al. This is an open access article distributed under the terms of Creative Commons Attribution License, which permits unrestricted use, distribution, and reproduction in any medium, provided the original author and source are credited.

\section{INTRODUCTION}

In December 2019, a cluster of patients with pneumonia of unknown cause (named COVID-19 on February 12, 202011) was linked to a seafood wholesale market in Wuhan, Hubei, China. ${ }^{2,3}$ In the next 2 months, the outbreak spread to the rest of the provinces. On January 8, 2020, a novel coronavirus (named SARS-CoV-2 a month later ${ }^{4}$ ) was laboratory confirmed as the cause of the outbreak, similar to the severe acute respiratory syndrome coronavirus (SARS-CoV) ${ }^{5}$ that caused severe acute respiratory syndrome outbreaks in China in 2003 and the Middle East respiratory syndrome coronavirus (MERS-CoV) ${ }^{6}$ that caused severe respiratory disease outbreaks in the Middle East in 2012. Since January 3, China began to report the outbreak information to the World Health Organization (WHO) regularly. ${ }^{7}$ The test kit was initially developed on January 10. As of January 28 (when this study started), COVID-19 infection caused 5,974 cases in Mainland China and the number was growing dramatically. ${ }^{8}$ As of February 1 (when this study ended), 14,380 cases were reported. ${ }^{9}$ Currently COVID-19 has caused a global pandemic, with more than 6 million cases and more than 370,000 deaths reported in 216 countries and territories by the end of May $2020^{10}$ (See eFigure 1 for detailed timeline).

The dissemination of epidemic information and personal protection knowledge plays an important role in preventing and controlling the outbreak. The evidence suggested that human-tohuman transmission had occurred among close contacts, ${ }^{11,12}$ and the basic reproductive number $\left(\mathrm{R}_{0}\right)$ was estimated approximately as 2.68. ${ }^{13}$ The outbreak coincided with the Chinese Lunar New Year, and the mobility of people visiting relatives and friends increased, which also increased the difficulty of prevention and control. To improve the awareness of self-protection among the general population, the National Health Commission had released six versions of the new coronavirus pneumonia prevention and control protocol ${ }^{14}$ and published guidelines for public prevention, recommending minimizing outings, wearing a mask, and keeping hands clean. ${ }^{15}$ These suggestions, as well as daily outbreak information, are transmitted to the public through television,

Address for correspondence. Fuqiang Cui, MD, PhD, Department of Laboratorial Science and Technology, School of Public Health, Peking University, 38 Xueyuan Road, Haidian District, Beijing 100191, China (e-mail: cuifuq@126.com).

*Contributed equally to this paper 
mobile phones, the internet, and other means. People have discussed the outbreak and expressed their views in "we media" era during the spread of the outbreak. Due to the rapid spread of the outbreak and the control activities, some people developed anxiety and fear. Guidance on emergency psychological crisis intervention was published for patients, medical professionals, and the general public to prevent the psychological damage caused by the outbreak and promote social stability. ${ }^{16}$ Psychological assistance hotlines have been set up in all cities and counties, providing free 24 -hour service. ${ }^{17}$

To our knowledge, there has been no article reporting the current public awareness and psychological status of Chinese people focused on virus and epidemiology of outbreak. Understanding the public knowledge, practice of prevention, and psychological status can improve effectiveness of health risk communications, and analyzing their demographic differences can help avoid unequal protection across society. ${ }^{18}$ Therefore, at the beginning of the COVID-19 outbreak in China, we designed an online questionnaire to measure the knowledge and practice, providing references for reassuring citizens and outbreak control.

\section{METHODS}

\section{Study population}

A cross-sectional, population-based online survey was conducted from January 28 to February 1, 2020. It was an open online questionnaire for all the population aged 18 years or above residing in China and abroad. Those willing to respond could complete the questionnaire by mobile phone or by computer.

\section{Online questionnaire}

We designed a structured Chinese questionnaire and collected data on Wenjuanxing, an online platform providing functions equivalent to Amazon Mechanical Turk. In the questionnaire, we collected the following information: (1) the socio-demographic information of the respondents; (2) knowledge of COVID-19, including the transmission routes, susceptible population, incubation period and response principle (total, 6 questions); (3) practices of preventive measures against COVID-19, including wearing masks, personal hygiene practices, avoidance of contact with high risk group (total, 4 questions); (4) anxiety towards COVID-19, using the five-question short form of the State-Trait Anxiety Inventory (STAI) to measure anxiety; (5) risky behavior, defined as coming in contact with someone with a confirmed or suspected case; and (6) perceived risks, including five categorical options (No risk, Low risk, Medium risk, High risk, Very high risk). The questionnaire consisted of 33 questions and can be completed in 3-5 minutes (see eMaterials 1).

\section{Data management and statistical analysis}

We used SPSS (version 20.0, IBM, Armonk, NY, USA) and STATA (version 15.1, StataCorp LLC, College Station, TX, USA) for data cleaning and statistical analysis. Categorical variables were expressed as absolute and relative frequencies in different groups. According to the following principle, we calculated scores: (1) Knowledge of COVID-19, measured using "knowledge scores": questions were scored "1 point" (correct answer) or "0 point" (wrong answer or incomplete answer in multiple choices); (2) Practices of preventive measures against COVID-19, measured using "practices scores": questions were scored "1 point" (correct practice) or "0 point" (wrong practice);
(3) Anxiety towards COVID-19, measured using a five-point Likert-type scale to ascertain the degree of anxiety for five questions (from 1 to $5,1=$ never, $2=$ little, $3=$ sometimes, $4=$ often, 5 = always; total "anxiety scores" ranged from 5 to 25 ; in order to compare the relative level of anxiety among people with different characteristics, we defined anxiety scores of $\leq 25$ th percentile as low anxiety levels, 25 th-75th percentile as moderate anxiety levels, and $\geq 75$ th percentile as high anxiety levels); (4) risk behavior, categorized as a binary variable $(1=$ have, $0=$ don't have); and (5) perceived risks, which were divided into five order categories according to severity (from 1 to $5,1=$ no risk, $2=$ low risk, $3=$ medium risk, $4=$ high risk, $5=$ very high risk).

Direct standardized questionnaire was used to measure knowledge scores, practices scores, and anxiety scores on different ages and educations of population to improve comparability among provinces. General linear modeling (GLM) was used to identify associations of sociodemographic factors (eg, sex, age, and education) with knowledge scores, practices scores, and anxiety scores. We used trend linear regression to test the change trend of scores in people with different age and education. Binary logistic regression was used to explore the relationship between risk behaviors and wearing masks and hand hygiene, and odds ratios (ORs) and their 95\% confidence intervals (CIs) were calculated. The component ratio was used to describe the channel through which people obtained information.

The spatial data analyses were conducted using ArcGIS (version 10.2, ESRI Corp, Redlands, CA, USA). The significance level was considered when $P$ values were less than 0.05 .

\section{Quality control}

We monitored the progress of the survey every day. After the deadline, we checked the accuracy of data, and excluded the questionnaire if (1) the age range was below 18 or above 100 years, (2) the answering time was less than 150 seconds, or (3) there were logical contradictions between the answers to the questionnaire.

\section{Ethical approval}

This study was approved as ethical exemption by the Peking University Health Science Center Ethics Committee (IRB00001052). All subjects participated in the survey voluntarily, and the information in the database was completely de-identified.

\section{RESULTS}

\section{Study participants and characteristics}

In total, 10,966 individuals participated in this online survey. Among these, 1,202 were excluded due to out of age range or incomplete questionnaire, and the rate of completeness was $89.0 \%(9,764 / 10,966)$ (See eFigure 2).

The participants of this study covered all 31 provincial administrative regions in Mainland China. Among the 9,764 eligible participants, 156 (1.6\%) were from Hubei Province, 9,408 (96.4\%) were from other provinces in China (Mainly from Beijing, Shandong, Sichuan, and Guangxi), and 200 (2.0\%) were from abroad; 3,278 (33.6\%) was male; average age was 38.0 (standard deviation [SD], 12.0) years; 9,281 (95.1\%) were with senior high school education or above; 7,841 (80.3\%) were urban people; and 6,681 (67.8\%) were married (Figure 1A, Table 1). 


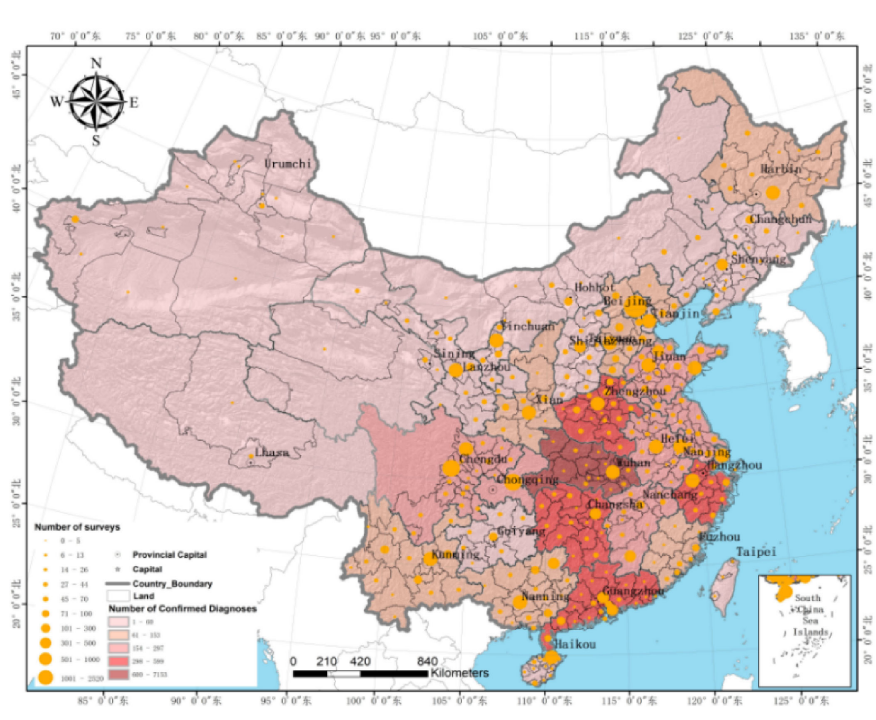

(A) Sample size and number of cases distributed in China

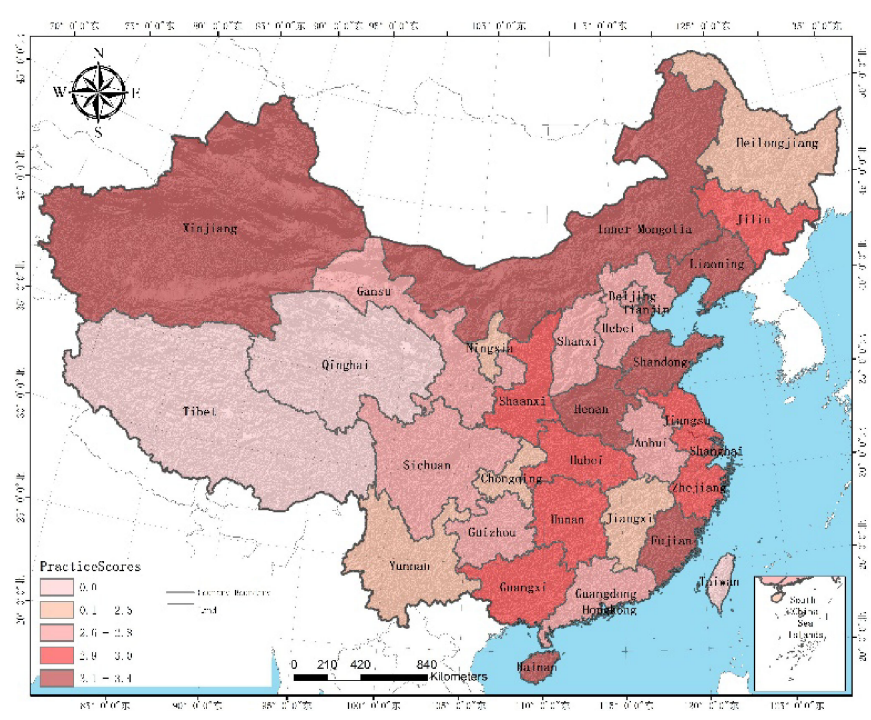

(C) Practice scores distribution in different provinces

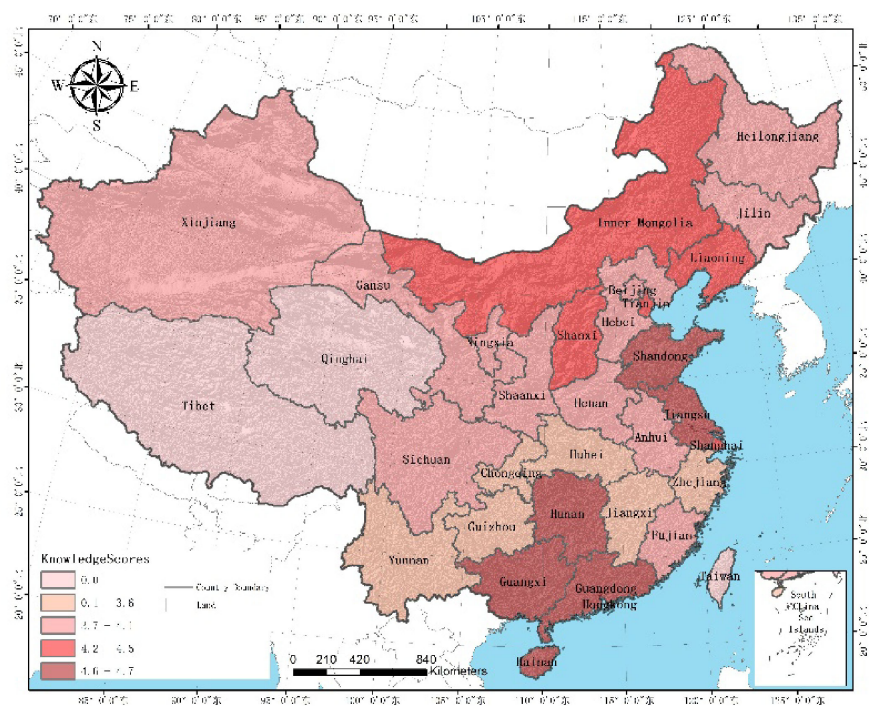

(B) Knowledge scores distribution in different provinces

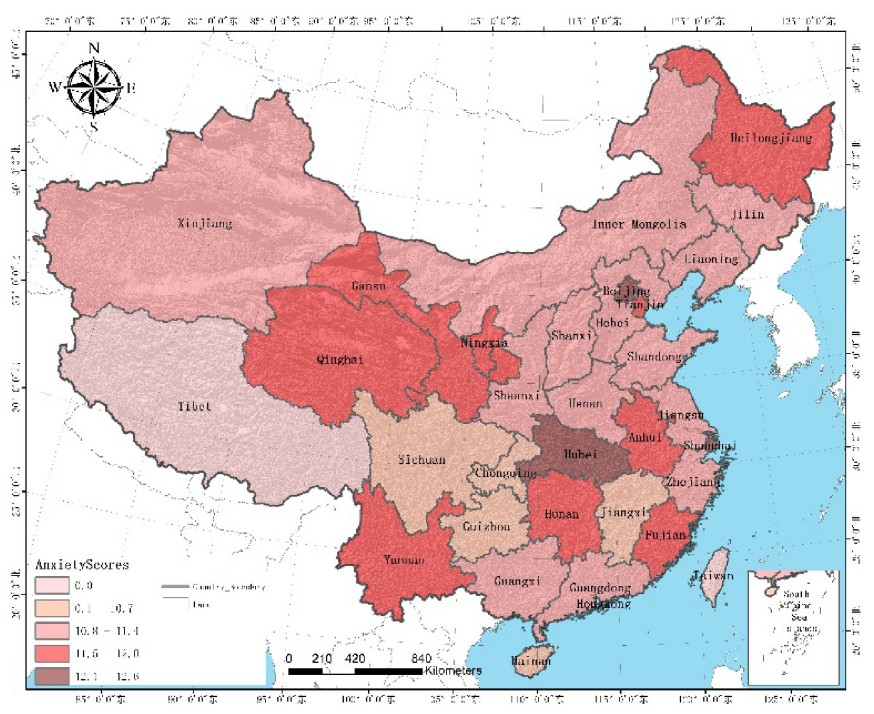

(D) Anxiety scores distribution in different provinces

Note: Data outside China are not shown in the figure

Figure 1. Distribution of case numbers, sample sizes, and knowledge/practice/anxiety scores by provinces in China

\section{Distribution of knowledge scores}

Average knowledge score of all respondents was 4.7 (SD, 1.0). $77.3 \%$ of respondents $(7,549 / 9,764)$ accurately knew the transmission route of COVID-19, and 95.4\% $(9,311 / 9,764)$ knew the incubation period of the disease.

Males had slightly lower knowledge scores than females (mean 4.6 vs $4.7 ; P<0.05)$. People over 50 years had lower knowledge scores (mean, 4.5; $P<0.01$ ). With the increase of education, people obtained higher knowledge scores $(P<0.01)$. Knowledge scores of medical personnel were higher than those in people with other occupations. There was no significant difference of knowledge scores in people with different marriage status (Table 2).

After adjustment for age and education, we found differences existing among provinces: Guangxi, Guangdong, Hainan, and other southern provinces of China had higher knowledge scores
(Figure 1B). The knowledge score from Hubei participants was significantly lower than other provinces participants' score ( $\beta=0.2, P<0.01)$ but not statistically different with those in people abroad $(\beta=0.0, P=0.72)$ (Table 2$)$.

\section{Distribution of practice scores}

The average practice score was 3.1 (SD, 0.9). $66.9 \%$ of respondents $(6,535 / 9,764)$ were able to wear appropriate masks to prevent COVID-19 infection, and $81.5 \%(5,323 / 6,535)$ were able to change their masks regularly. $96.1 \%$ of people $(9,386 /$ $9,764)$ maintained hand hygiene and washed their hands in time.

Males had lower practice scores than females (mean, 2.9 vs $3.2, P<0.01)$. People over 40 years old had lower practice scores $(P<0.01)$. People with senior high school education and above and medical professionals obtained higher practice scores (both 
Han B, et al.

Table 1. The characteristic of valid participants in online survey, China, 2020

\begin{tabular}{|c|c|c|c|c|}
\hline Characteristics & $\begin{array}{l}\text { From Hubei province } \\
n(\%)\end{array}$ & $\begin{array}{l}\text { From other provinces in China } \\
\qquad n(\%)\end{array}$ & $\begin{array}{c}\text { From abroad } \\
n(\%)\end{array}$ & $\begin{array}{l}\text { Total } \\
n(\%)\end{array}$ \\
\hline \multicolumn{5}{|l|}{ Gender } \\
\hline Female & $98(62.8)$ & $6,257(66.5)$ & $131(65.5)$ & $6,486(66.4)$ \\
\hline Male & $58(37.2)$ & $3,151(33.5)$ & $69(34.5)$ & 3,278 (33.6) \\
\hline \multicolumn{5}{|l|}{ Age group, years } \\
\hline$<30$ & $56(35.9)$ & $2,611(27.8)$ & $58(29.0)$ & $2,725(27.9)$ \\
\hline $30-39$ & $44(28.2)$ & $2,741(29.1)$ & $73(36.5)$ & $2,858(29.3)$ \\
\hline $40-49$ & $35(22.4)$ & $2,309(24.5)$ & $38(19.0)$ & $2,382(24.4)$ \\
\hline$\geq 50$ & $21(13.5)$ & $1,747(18.6)$ & $31(15.5)$ & $1,799(18.4)$ \\
\hline \multicolumn{5}{|l|}{ Education } \\
\hline Junior high school and below & $5(3.2)$ & $474(5.0)$ & $4(2.0)$ & $483(4.9)$ \\
\hline Senior high school & $20(12.8)$ & $1,279(13.6)$ & $16(8.0)$ & $1,315(13.5)$ \\
\hline Bachelor's degree & $91(58.3)$ & $5,372(57.1)$ & $86(43.0)$ & $5,549(56.8)$ \\
\hline Master's degree or above & $40(25.6)$ & $2,283(24.3)$ & $94(47.0)$ & $2,417(24.8)$ \\
\hline \multicolumn{5}{|l|}{ Marriage } \\
\hline Married & $91(58.3)$ & $6,392(67.9)$ & $135(67.5)$ & $6,618(67.8)$ \\
\hline Unmarried & $62(39.7)$ & $2,664(28.3)$ & $63(31.5)$ & $2,789(28.6)$ \\
\hline Divorced & $3(1.9)$ & $255(2.7)$ & $2(1.0)$ & $260(2.7)$ \\
\hline Widowed & 0 & $56(0.6)$ & 0 & $56(0.6)$ \\
\hline Other & 0 & $41(0.4)$ & 0 & $41(0.4)$ \\
\hline \multicolumn{5}{|l|}{ Occupation } \\
\hline Medical professional & $23(14.7)$ & $1,717(18.3)$ & $18(9.0)$ & $1,758(18.0)$ \\
\hline Labors & $5(3.2)$ & $643(6.8)$ & $13(6.5)$ & $661(6.8)$ \\
\hline Teachers and researchers & $32(20.5)$ & $1,855(19.7)$ & $45(22.5)$ & $1,932(19.8)$ \\
\hline C\&S personnel & $30(19.2)$ & $1,910(20.3)$ & $58(29.0)$ & $1,998(20.5)$ \\
\hline Students & $37(23.7)$ & $1,161(12.3)$ & $33(16.5)$ & $1,231(12.6)$ \\
\hline Other & $29(18.6)$ & $2,122(22.6)$ & $33(16.5)$ & $2,184(22.4)$ \\
\hline \multicolumn{5}{|l|}{ Residence } \\
\hline Rural & $44(28.2)$ & $1,849(19.7)$ & $30(15.0)$ & $1,923(19.7)$ \\
\hline Urban & $112(71.8)$ & $7,559(80.3)$ & $170(85.0)$ & $7,841(80.3)$ \\
\hline Total & 156 & 9,408 & 200 & 9,764 \\
\hline
\end{tabular}

C\&S, commercial and service personnel.

$P<0.01)$. We did not find significant difference in people with different marriage status (Table 2).

After adjustments for age and education, provinces in China showed different practice scores. Inner Mongolia, Xinjiang, Liaoning, Tianjin, and other northern provinces had higher practice scores (Figure 1C). There was no significantly difference in practice scores between Hubei Province and other provinces $(\beta=-0.1, P=0.07)$ (Table 2).

\section{Anxiety scores in people with different character- istics}

We found that $90.3 \%(8,815 / 9,764)$ of participants had experienced varying levels of anxiety. Thirty-six percent $(3,518 / 9,764)$ people reported that they were frequently angry, and $33.8 \%$ $(3,304 / 9,764)$ people often had pessimism. Only 5.0\% (486/ $9,764)$ of people were not nervous about the outbreak. Among all participants, the median anxiety score was $11\left(\mathrm{P}_{25}=8 ; \mathrm{P}_{75}=15\right)$. The proportion of women $(30.6 \%)$ in high anxiety state was higher than that of men $(21.0 \%)$. With the increase of age, the anxiety of the population gradually decreased $(\beta=-0.2, P<$ $0.01)$. With the increase of education, the proportion of people with high anxiety level rose gradually $(15.3 \%, 20.7 \%, 28.3 \%$, and $31.4 \%$ for junior high school or above, senior high school, bachelor's degree, and master's degree or above, respectively); (Table 2). In addition, medical professional (32.0\%) and people living in urban area $(28.1 \%)$ had higher proportion in high anxiety than other people.
Based on the standardized anxiety scores, we found people in Hubei Province were the most anxious (37.2\% with high anxiety), followed by those living in Beijing (30.5\% with high anxiety) and Shanghai $(30.2 \%$ with high anxiety) (Figure 1D). The results of GLM showed that the anxiety of people in Hubei Province (mean, 12.6) was much higher than that of other provinces in China (mean, 11.5, $P<0.01$ ) and abroad $($ mean $=11.7, P<0.05$ ) (Table 2).

\section{Perceived risks and behavior in wearing masks and hand hygiene}

In this study, $86.5 \%$ of people in Hubei Province reported that they have been in contact with someone with a confirmed or suspected case, compared with only $6.5 \%$ of people in other provinces. Compared to females, males did not want to wear a mask to go out (4.2\% vs $2.2 \%$; OR 0.5 ; 95\% CI, 0.4-0.6) or clean their hands frequently (5.4\% vs $3.1 \%$; OR 0.5 ; 95\% CI, $0.4-0.7)$. People over 30 years were more likely to wear masks than those under 30 years (OR 2.4; 95\% CI, 1.8-3.4 for 30-39 year olds, OR 2.7; 95\% CI, 1.9-3.9 for those aged 40-49 years, and OR 2.2; 95\% CI, 1.6-3.2 for those aged $\geq 50$ years). The perceived risk and the possibility of wearing masks and hand hygiene of the people in Hubei Province were not significantly different from those in other provinces $(P=0.76, P=0.66$, and $P=0.32$, respectively). After adjusting for gender, age, education, and province, people with risk behaviors could clearly know that they were at high risk $(\beta=0.3, P<0.01)$. However, people who had 
Awareness, Practice, and Anxiety for COVID-19

Table 2. Knowledge scores, practice scores and anxiety scores by subject characteristics in General Linear Model (GLM), China, 2020

\begin{tabular}{|c|c|c|c|c|c|c|c|}
\hline \multirow{2}{*}{ Characteristics } & \multirow{2}{*}{ Number } & \multicolumn{3}{|c|}{ Knowledge scores } & \multicolumn{3}{|c|}{ Practice scores } \\
\hline & & Mean & $\beta$ & $\mathrm{t}$ & Mean & $\beta$ & $\mathrm{t}$ \\
\hline \multicolumn{8}{|l|}{ Gender } \\
\hline Female $^{\text {Ref }}$ & 6,486 & 4.7 & & & 3.2 & & \\
\hline Male & 3,278 & 4.6 & 0.0 & $-2.3^{\mathrm{a}}$ & 2.9 & -0.2 & $-11.9^{b}$ \\
\hline \multicolumn{8}{|l|}{ Age group, years } \\
\hline$<30^{\operatorname{Ref}}$ & 2,725 & 4.7 & & & 3.3 & & \\
\hline $30-39$ & 2,858 & 4.8 & 0.1 & $2.6^{\mathrm{a}}$ & 3.2 & 0.0 & -1.3 \\
\hline $40-49$ & 2,382 & 4.7 & 0.0 & 1.0 & 3.0 & -0.2 & $-6.5^{\mathrm{b}}$ \\
\hline$\geq 50$ & 1,799 & 4.5 & -0.1 & $-3.0^{\mathrm{b}}$ & 2.8 & -0.4 & $-10.9^{b}$ \\
\hline \multicolumn{8}{|l|}{ Education } \\
\hline Junior high school and below ${ }^{\text {Ref }}$ & 483 & 4.0 & & & 2.8 & & \\
\hline Senior high school & 1,315 & 4.3 & 0.4 & $7.2^{\mathrm{b}}$ & 3.0 & 0.2 & $3.3^{b}$ \\
\hline Bachelor's degree & 5,549 & 4.8 & 0.7 & $14.7^{\mathrm{b}}$ & 3.1 & 0.2 & $5.7^{\mathrm{b}}$ \\
\hline Master's degree or above & 2,417 & 4.9 & 0.9 & $15.9^{\mathrm{b}}$ & 3.2 & 0.3 & $5.4^{\mathrm{b}}$ \\
\hline \multicolumn{8}{|l|}{ Marriage } \\
\hline Married $^{\text {Ref }}$ & 6,618 & 4.7 & & & 3.1 & & \\
\hline Unmarried & 2,789 & 4.7 & 0.0 & -0.6 & 3.2 & 0.0 & 0.4 \\
\hline Divorced & 260 & 4.6 & 0.0 & -0.1 & 3.1 & 0.0 & 0.3 \\
\hline Widowed & 56 & 4.4 & -0.1 & -0.8 & 2.8 & -0.2 & -1.5 \\
\hline Other & 41 & 4.3 & -0.3 & $-2.0^{\mathrm{a}}$ & 3.0 & 0.0 & -0.1 \\
\hline \multicolumn{8}{|l|}{ Occupation } \\
\hline Medical professional ${ }^{\operatorname{Ref}}$ & 1,758 & 4.9 & & & 3.2 & & \\
\hline Labors & 661 & 4.3 & -0.3 & $-5.7^{\mathrm{b}}$ & 2.8 & -0.2 & $-4.4^{\mathrm{b}}$ \\
\hline Teachers and researchers & 1,932 & 4.8 & -0.2 & $-6.4^{\mathrm{b}}$ & 3.1 & -0.1 & $-2.1^{\mathrm{a}}$ \\
\hline C\&S personnel & 1,998 & 4.7 & -0.2 & $-7.0^{\mathrm{b}}$ & 3.1 & -0.1 & $-3.1^{\mathrm{b}}$ \\
\hline Students & 1,231 & 4.7 & -0.2 & $-4.7^{\mathrm{b}}$ & 3.2 & -0.1 & $-3.4^{\mathrm{b}}$ \\
\hline Other & 2,184 & 4.6 & -0.3 & $-7.8^{\mathrm{b}}$ & 3.0 & -0.1 & $-3.9^{\mathrm{b}}$ \\
\hline \multicolumn{8}{|l|}{ Urban/Rural } \\
\hline Rural $^{\text {Ref }}$ & 1,923 & 4.6 & & & 3.1 & & \\
\hline Urban & 7,841 & 4.7 & 0.0 & 1.0 & 3.1 & 0.1 & $3.2^{\mathrm{b}}$ \\
\hline \multicolumn{8}{|l|}{ Area } \\
\hline Hubei province ${ }^{\text {Ref }}$ & 156 & 4.5 & & & 3.3 & & \\
\hline Other provinces in China & 9,408 & 4.7 & 0.2 & $3.0^{\mathrm{b}}$ & 3.1 & -0.1 & -1.8 \\
\hline Abroad & 200 & 4.6 & 0.0 & 0.4 & 2.9 & -0.4 & $-4.5^{\mathrm{b}}$ \\
\hline Total & 9,764 & 4.7 & & & 3.1 & & \\
\hline
\end{tabular}

Continued on next page.

experienced risk behaviors were less likely to wear masks and practice good hand hygiene than those without risk behaviors (OR 0.6, $P=0.03$ and OR 0.8, $P=0.19$, respectively) (Table 3 ).

\section{Interest and channel preference for epidemic in- formation of respondents}

Most $(97.6 \% ; 9,525 / 9,764)$ of the respondents paid attention to the epidemic information every day; $79.0 \% \quad(7,717 / 9,764)$ believed the outbreak would be fully controlled within 3 months; and $93.9 \%(9,165 / 9,764)$ of the respondents obtained epidemic information through official announcement, followed by social media (61.4\%) and traditional media (54.1\%) (Figure 2).

\section{DISCUSSION}

Our study demonstrated that this COVID-19 outbreak had attracted widespread public attention in China, with nearly $98 \%$ of the population continuously tracking the situation, and nearly $80 \%$ of them had the confidence that the government could control the outbreak. More than two-thirds of the public had high level awareness of COVID-19 and the precaution measures; however, regional differences exist. At the beginning of the COVID-19 outbreak in China, people in Hubei, Beijing, and Shanghai had more anxiety than those in other provinces.
At the beginning of the COVID-19 outbreak, a rapid response and an open, transparent system for epidemic reporting and news briefing are of great significance to improve people's confidence in epidemic prevention and control. The epidemic can generally be controlled effectively through syndromic (fever) surveillance, contact tracing, quarantine, and self-protection, just like SARScov and MERS-cov. ${ }^{19}$ Therefore, China had strongly restricted movement across Hubei Province and then escalated it to the rest of the provinces in a short period. ${ }^{20}$ Our research found that the internet media and mobile media played a very important role in the publicity and communication of epidemic prevention and control, with more than two-thirds of the respondents getting the outbreak news and official announcements through online media, such as official website, Weibo, and WeChat. In China, there were 112.2 mobile phones per 100 people on average in $2018,{ }^{21}$ which provides a guarantee for the government to guide people to strengthen self-protection online. In fact, more than three-fourths of people accurately understood the transmission route, incubation period, and preventive measures of COVID-19 because of the spread of official information. It is very important for people to know the accurate information of the disease, especially the prevention measures, which play an important role in the prevention and control of the outbreak. In the study, 95.4\% of the respondents knew the incubation period of COVID-19. In 
Han B, et al.

\begin{tabular}{|c|c|c|c|c|c|}
\hline \multirow{2}{*}{ Characteristics } & \multirow{2}{*}{ Number } & \multicolumn{4}{|c|}{ Anxiety scores } \\
\hline & & Low & Moderate & High & $\chi^{2}$ \\
\hline \multicolumn{6}{|l|}{ Gender } \\
\hline Female & 6,486 & $1,654(25.5)$ & $2,845(43.9)$ & 1,987 (30.6) & $156.0^{\mathrm{b}}$ \\
\hline Male & 3,278 & $1,178(35.9)$ & $1,412(43.1)$ & $688(21.0)$ & \\
\hline \multicolumn{6}{|l|}{ Age group, years } \\
\hline$<30$ & 2,725 & $633(23.2)$ & $1,239(45.5)$ & $853(31.3)$ & $266.8^{\mathrm{b}}$ \\
\hline $30-39$ & 2,858 & $711(24.9)$ & $1,221(42.7)$ & $926(32.4)$ & \\
\hline $40-49$ & 2,382 & $755(31.7)$ & $1,027(43.1)$ & $600(25.2)$ & \\
\hline$\geq 50$ & 1,799 & $733(40.7)$ & $770(42.8)$ & $296(16.5)$ & \\
\hline \multicolumn{6}{|l|}{ Education } \\
\hline Junior high school and below & 483 & $198(41.0)$ & $211(43.7)$ & $74(15.3)$ & $141.4^{\mathrm{b}}$ \\
\hline Senior high school & 1,315 & $497(37.8)$ & $546(41.5)$ & $272(20.7)$ & \\
\hline Bachelor's degree & 5,549 & $1,538(27.7)$ & $2,440(44.0)$ & $1,571(28.3)$ & \\
\hline Master's degree or above & 2,417 & $599(24.8)$ & $1,060(43.9)$ & 758 (31.4) & \\
\hline \multicolumn{6}{|l|}{ Marriage } \\
\hline Married & 6,618 & $1,987(30.0)$ & $2,865(43.3)$ & $1,766(26.7)$ & $42.4^{\mathrm{b}}-\mathrm{r} \cdot \mathrm{c} \cdot \mathrm{c}$ \\
\hline Unmarried & 2,789 & 709 (25.4) & $1,254(45.0)$ & 826 (29.6) & \\
\hline Divorced & 260 & $101(38.8)$ & $94(36.2)$ & $65(25.0)$ & \\
\hline Widowed & 56 & $20(35.7)$ & $29(51.8)$ & $7(12.5)$ & \\
\hline Other & 41 & $15(36.6)$ & 15 (36.6) & $11(26.8)$ & \\
\hline \multicolumn{6}{|l|}{ Occupation } \\
\hline Medical professional & 1,758 & $461(26.2)$ & $735(41.8)$ & $562(32.0)$ & $103.0^{\mathrm{b}}$ \\
\hline Labors & 661 & $260(39.3)$ & $263(39.8)$ & $138(20.9)$ & \\
\hline Teachers and researchers & 1,932 & $602(31.2)$ & $872(45.1)$ & $458(23.7)$ & \\
\hline C\&S personnel & 1,998 & $579(29.0)$ & $879(44.0)$ & $540(27.0)$ & \\
\hline Students & 1,231 & $270(21.9)$ & $573(46.5)$ & $388(31.5)$ & \\
\hline Other & 2,184 & $660(30.2)$ & $935(42.8)$ & $589(27.0)$ & \\
\hline \multicolumn{6}{|l|}{ Urban/Rural } \\
\hline Rural & 1,923 & $582(30.3)$ & $871(45.3)$ & $470(24.4)$ & $10.5^{\mathrm{b}}$ \\
\hline Urban & 7,841 & $2,250(28.7)$ & $3,386(43.2)$ & $2,205(28.1)$ & \\
\hline \multicolumn{6}{|l|}{ Area } \\
\hline Hubei province & 156 & $26(16.7)$ & $72(46.2)$ & $58(37.2)$ & $15.2^{\mathrm{b}}$ \\
\hline Other provinces in China & 9,408 & $2,749(29.2)$ & 4,103 (43.6) & $2,556(27.2)$ & \\
\hline Abroad & 200 & $57(28.5)$ & $82(41.0)$ & $61(30.5)$ & \\
\hline Total & 9,764 & 2,832 & 4,257 & 2,675 & \\
\hline
\end{tabular}

$\mathrm{C} \& \mathrm{~S}$, commercial and service personnel; Ref, reference group.

${ }^{\mathrm{a}} P<0.05$.

${ }^{\mathrm{b}} P<0.01$.

contrast to China, a study from Saudi Arabia showed that people had a high awareness of transmission routes and clinical symptoms of MERS-CoV but a low awareness of its incubation period. ${ }^{22}$ Young adults appeared as being more active in terms of knowledge. We considered that this difference may be caused by the popularity of mobile phones and the internet. About $50 \%$ of people currently infected with COVID-19 are over 50 years old in China. ${ }^{23}$ Therefore, what deserves our attention is the improvement of epidemic knowledge of people over 50 years old, especially in Hubei Province.

We found that $66.9 \%$ of respondents were able to wear appropriate masks to prevent COVID-19 infection, $81.5 \%$ were able to change their masks regularly, and $96.1 \%$ of people maintained hand hygiene and washed their hands frequently. WHO and United States Centers for Disease Control and Prevention does not recommend wearing masks to prevent infection and suggests hand-washing as a protective measure for general population as of the completion of this investigation. ${ }^{24,25}$ However, based on Chinese guidelines, we could conclude that more than $30 \%$ of respondents were not able to wear appropriate masks to prevent COVID-19 infection, and nearly 20\% did not change their masks regularly. The proportion of people taking preventive measures is similar to that among the population in Reunion Island during the influenza A (H1N1) pandemic, ${ }^{26}$ but still low. Previous literature showed that the relationship between age and preventive behavior may change with different diseases and different population. ${ }^{26-28}$ Reducing the misunderstanding of personal protection is the focus of public awareness and health education in the next step.

Our study confirmed that anxiety related to COVID-19 outbreak was common in the general population. Anxiety and fear has a negative impact not only on health, but also has economic effects and social consequences, as was seen during the SARS outbreak in 2003. ${ }^{29}$ In addition to Hubei Province, people in multiple provinces, like Shanghai and Beijing, also had experienced much anxiety. Cities that experienced previous outbreaks might be more sensitive to the epidemic of infectious diseases. ${ }^{30,31}$ Younger people living in urban areas or with higher education were more anxious about the outbreak, which showed similar trends observed for anxiety and panic during the H5N1 avian influenza pandemic in Hong Kong ${ }^{32}$ and during the SARS outbreak in Qatar. ${ }^{33}$ While COVID-19 is still spreading across the country, the public generally experiences high levels of panic, fear, anxiety, and irritability. These negative emotions can 
Table 3. Ability to perceive risk and behavior in wearing masks in people with different characteristics especially those with risk behaviors, China, 2020

\begin{tabular}{|c|c|c|c|c|c|c|c|c|}
\hline \multirow{2}{*}{ Characteristics } & \multirow{2}{*}{ Number } & \multicolumn{3}{|c|}{ Perceived risks } & \multicolumn{2}{|c|}{ Wearing masks } & \multicolumn{2}{|c|}{ Cleaning hands } \\
\hline & & Mean & $\beta$ & $t$ & $N(\%)$ & OR $(95 \% C I)$ & $N(\%)$ & OR $(95 \% C I)$ \\
\hline \multicolumn{9}{|l|}{ Gender } \\
\hline Female $^{\text {Ref }}$ & 6,486 & & & & $6,342(97.8)$ & & $6,286(96.9)$ & \\
\hline Male & 3,278 & 2.2 & 0.0 & -1.7 & $3,140(95.8)$ & $0.5(0.4-0.6)^{\mathrm{b}}$ & $3,100(94.6)$ & $0.5(0.4-0.7)^{\mathrm{b}}$ \\
\hline \multicolumn{9}{|l|}{ Age group, years } \\
\hline$<30^{\operatorname{Ref}}$ & 2,725 & & & & $2,599(95.4)$ & & $2,591(95.1)$ & \\
\hline $30-39$ & 2,858 & 2.2 & 0.1 & $2.4^{\mathrm{a}}$ & $2,799(97.9)$ & $2.4(1.8-3.4)^{\mathrm{b}}$ & $2,772(97.0)$ & $1.8(1.3-2.3)^{\mathrm{b}}$ \\
\hline $40-49$ & 2,382 & 2.2 & 0.0 & 1.0 & $2,333(97.9)$ & $2.7(1.9-3.9)^{\mathrm{b}}$ & $2,314(97.1)$ & $2.2(1.6-2.9)^{\mathrm{b}}$ \\
\hline$\geq 50$ & 1,799 & 2.2 & -0.1 & $-2.8^{\mathrm{b}}$ & $1,751(97.3)$ & $2.2(1.6-3.2)^{\mathrm{b}}$ & $1,709(95.0)$ & $1.3(1.0-1.7)$ \\
\hline \multicolumn{9}{|l|}{ Education } \\
\hline $\mathrm{J} \& \mathrm{~B}^{\mathrm{Ref}}$ & 483 & & & & $441(91.3)$ & & $415(85.9)$ & \\
\hline Senior high school & 1,315 & 2.0 & 0.0 & 1.1 & $1,258(95.7)$ & $2.3(1.5-3.6)^{\mathrm{b}}$ & $1,227(93.3)$ & $2.5(1.8-3.5)^{\mathrm{b}}$ \\
\hline Bachelor's degree & 5,549 & 2.0 & 0.2 & $5.2^{\mathrm{b}}$ & $5,422(97.7)$ & $5.1(3.5-7.4)^{b}$ & $5,396(97.2)$ & $6.4(4.7-8.8)^{b}$ \\
\hline Master's degree or above & 2,417 & 2.2 & 0.2 & $5.3^{\mathrm{b}}$ & $2,361(97.7)$ & $5.2(3.4-8.0)^{\mathrm{b}}$ & $2,348(97.1)$ & $5.9(4.1-8.5)^{\mathrm{b}}$ \\
\hline \multicolumn{9}{|l|}{ Area } \\
\hline Hubei province ${ }^{\text {Ref }}$ & 156 & & & & $151(96.8)$ & & $146(93.6)$ & \\
\hline Other provinces in China & 9,408 & 2.5 & 0.0 & -0.3 & $9,153(97.3)$ & $0.8(0.3-2.1)$ & $9,047(96.2)$ & $1.4(0.7-3.0)$ \\
\hline Abroad & 200 & 2.2 & -0.1 & -1.4 & $178(89.0)$ & $0.2(0.1-0.4)^{\mathrm{b}}$ & $193(96.5)$ & $1.3(0.5-3.8)$ \\
\hline \multicolumn{9}{|l|}{ Risk behaviors } \\
\hline $\mathrm{No}^{\text {Ref }}$ & 9,006 & & & & $8,757(97.2)$ & & $8,666(96.2)$ & \\
\hline Yes & 758 & 2.1 & 0.3 & $10.0^{\mathrm{b}}$ & $725(95.6)$ & $0.6(0.4-1.0)^{\mathrm{a}}$ & $720(95.0)$ & $0.8(0.5-1.1)$ \\
\hline
\end{tabular}

CI, confidence interval; J\&B, junior high school and below; OR, odds ratio; Ref, reference group.

${ }^{\mathrm{a}} P<0.05$.

${ }^{\mathrm{b}} P<0.01$.

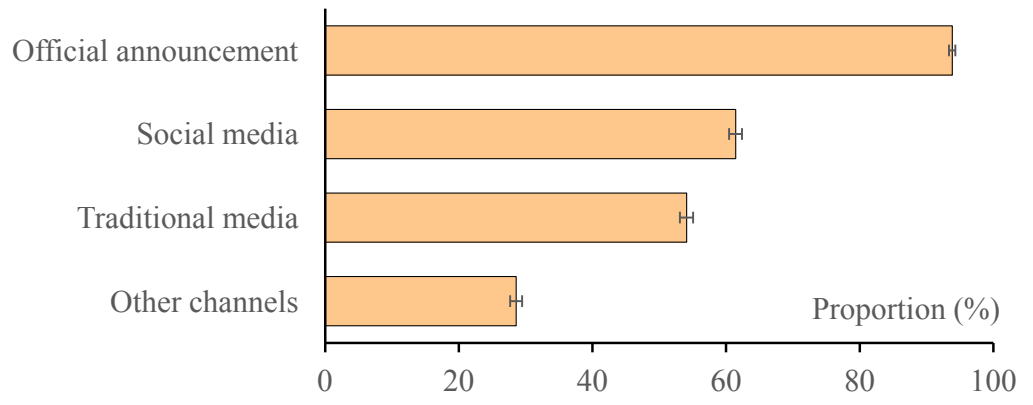

Figure 2. Channel preference for COVID-19 outbreak information reporting and seeking, China, 2020

progress into behavioral changes, such as being afraid to leave the house, blindly disinfecting, and scrambling for medicines. Baidu, one of the most common search engines in China, has released an information index, for which "psychological counseling" in Hubei Province increased by $3,275 \%$ from January 20th to January 26th, and the search index increased by $51 \%$ in the 7 days. ${ }^{34}$ In this study, $86.5 \%$ of people in Hubei Province reported that they had contacted high-risk population or environment, compared with only $6.5 \%$ of people in other provinces. Besides, many areas have cut off traffic with Hubei. This would increase their psychological stress. These results suggested we should not only support Hubei Province in medical treatment, but also need to strengthen health education and psychological counseling. It is recognized that extensively implementing mental health monitoring in the community is a worthwhile strategy. Community workers should regularly assess the psychological status of community families and report to their superiors. Meanwhile, the government should strengthen media efforts to ensure the validity and accuracy of output information. We strongly recommend that the government develop health education strategies to address mental health issues, promote healthy behaviors, and reduce psychological stress.

In this study, people with risk behaviors clearly know that they were at high risk, but they did not pay enough attention to wearing a mask when going out and maintaining good hand hygiene. According to local regulations, people must wear masks when going out. What's more, maintaining hand hygiene is an effective protection for themselves. We consider that appropriate risk perception of the outbreak can lead to beneficial changes in health behaviors, such as wearing masks and washing hands frequently. And strong publicity and punishment may increase the possibility of wearing masks and other protective behaviors. However, due to the sudden outbreak, the supply of masks in China is insufficient to meet the needs of some people.

There are some limitations to our study. First, online questionnaires led to a biased selection. The respondents are mainly those living in urban area and with high school education or above, which may overestimate the knowledge of the outbreak and protection. Second, although we have carried out quality control, there may be errors in the information because the online 
questionnaire cannot be modified after filling in. Third, this study is a cross-sectional survey and cannot show trends. In order to dynamically assess knowledge, practice, and psychological pressure of Chinese people on the outbreak, we have conducted a follow-up survey while the epidemic was under control.

In summary, the public was very concerned about the COVID19 outbreak, with high knowledge of the transmission route and incubation period of the disease, and a high proportion of people practiced good hand hygiene behavior; however, quite a number of people experienced anxiety caused by quarantine or mobility control, especially in Hubei Province. The findings suggest the importance of closing the gap between knowledge and good practice, and the need to reduce anxiety caused by the pandemic. Conducting psychological counseling and health education to public and patients is an important and key measures to address the public anxiety issue.

\section{ACKNOWLEDGMENTS}

We thank Dr. Stephen C. Hadler of the Centers for Disease Control and Prevention for his helpful comments and editing suggestions for the manuscript.

Conflicts of interest: None declared. There is no significant financial support for this work that could have influenced its outcome.

Funding source: This work was supported by Fundamental Research Funds for the Central Universities and Peking University Health Science Center [grant numbers BMU20170607].

\section{APPENDIX A. SUPPLEMENTARY DATA}

Supplementary data related to this article can be found at https:// doi.org/10.2188/jea.JE20200148.

\section{REFERENCES}

1. World Health Organization. WHO Director-General's remarks at the media briefing on 2019-nCoV on 11 February 2020. https://www. who.int/dg/speeches/detail/who-director-general-s-remarks-at-themedia-briefing-on-2019-ncov-on-11-february-2020. Accessed 20.02. 12.

2. Zhu N, Zhang D, Wang W, et al. A novel coronavirus from patients with pneumonia in China, 2019. N Engl J Med. 2020;382(8):727733.

3. Lu R, Zhao X, Li J, et al. Genomic characterisation and epidemiology of 2019 novel coronavirus: implications for virus origins and receptor binding. Lancet. 2020;395(10224):565-574.

4. Jiang S, Shi Z, Shu Y, et al. A distinct name is needed for the new coronavirus. Lancet. 2020;395(10228):949.

5. Zhong NS, Zheng BJ, Li YM, et al. Epidemiology and cause of severe acute respiratory syndrome (SARS) in Guangdong, People's Republic of China, in February, 2003. Lancet. 2003;362(9393):13531358.

6. Zaki AM, van Boheemen S, Bestebroer TM, Osterhaus AD, Fouchier RA. Isolation of a novel coronavirus from a man with pneumonia in Saudi Arabia. N Engl J Med. 2012;367(19):1814-1820.

7. Xinhua News Agency. Record of COVID-19 epidemic information in China. http://www.gov.cn/xinwen/2020-04/06/content_5499625. htm. Accessed 20.05.28 (in Chinese).

8. National Health Commission. The latest situation of COVID-19 outbreak as of January 28. http://www.nhc.gov.cn/xcs/yqtb/202001/ 1c259a68d81d40abb939a0781c1fe237.shtml. Accessed 20.05.28 (in Chinese).
9. National Health Commission. Outbreak notification. http://www. nhc.gov.cn/xcs/yqtb/202002/d5c495da742f4739b7f99339c3bd032f. shtml. Accessed 20.02.03 (in Chinese).

10. World Health Organization. Coronavirus disease (COVID-19) Situation Report - 133 https://www.who.int/docs/default-source/ coronaviruse/situation-reports/20200601-covid-19-sitrep-133.pdf? sfvrsn=9a56f2ac_4. Accessed 20.06.09.

11. Chan JF, Yuan S, Kok KH, et al. A familial cluster of pneumonia associated with the 2019 novel coronavirus indicating personto-person transmission: a study of a family cluster. Lancet. 2020; 395(10223):514-523

12. Li Q, Guan X, Wu P, et al. Early transmission dynamics in Wuhan, China, of novel coronavirus-infected pneumonia. $N$ Engl J Med. 2020;382(13):1199-1207.

13. Wu JT, Leung K, Leung GM. Nowcasting and forecasting the potential domestic and international spread of the 2019-nCoV outbreak originating in Wuhan, China: a modelling study. Lancet. 2020;395(10225):689-697.

14. National Health Commission. Notice of General Office of National Health Commission on Issuing a New Coronavirus Pneumonia Prevention and Control Plan (Sixth Edition). http://www.nhc.gov. $\mathrm{cn} / \mathrm{jkj} / \mathrm{s} 3577 / 202003 / 4856 \mathrm{~d} 5 \mathrm{~b} 0458141 \mathrm{fa} 9$ f376853224d41d7.shtml. Accessed 20.06.09 (in Chinese).

15. National Health Commission. Public prevention guidelines for the prevention and control of pneumonia in a new coronavirus infection. http://www.nhc.gov.cn/jkj/s3578/202001/ 3a13637e1a9249a2b6047f34b772b5e6.shtml. Accessed 20.02.02 (in Chinese).

16. National Health Commission. Guiding principles for emergency psychological crisis intervention for pneumonia outbreak of new coronavirus infection. http://www.nhc.gov.cn/jkj/s3577/202001/ 6adc08b966594253b2b791be5c3b9467.shtml. Accessed 20.02.02 (in Chinese).

17. Chinese Center for Disease Control and Prevention. Notice on Establishing a Psychological Assistance Hotline for Outbreak Response. http://www.chinacdc.cn/jkzt/crb/zl/szkb_11803/jszl_11813/ 202002/t20200203_212165.html. Accessed 20.02.03 (in Chinese).

18. Vaughan E, Tinker T. Effective health risk communication about pandemic influenza for vulnerable populations. Am J Public Health. 2009;99(Suppl 2):S324-S332.

19. Munster VJ, Koopmans M, van Doremalen N, van Riel D, de Wit E. A novel coronavirus emerging in China - key questions for impact assessment. N Engl J Med. 2020;382(8):692-694.

20. Phelan AL, Katz R, Gostin LO. The novel coronavirus originating in Wuhan, China: challenges for global health governance. JAMA. 2020;323(8):709-710.

21. Ministry of Industry and Information Technology. China Radio Management Annual Report (2018). http://www.miit.gov.cn/ n1146290/n1146402/n1146440/c6692260/content.html. Accessed 20.02.07 (in Chinese).

22. Almutairi KM, Al Helih EM, Moussa M, et al. Awareness, attitudes, and practices related to coronavirus pandemic among public in Saudi Arabia. Fam Community Health. 2015;38(4):332-340.

23. Epidemiology Working Group for NCIP Epidemic Response The epidemiological characteristics of an outbreak of 2019 novel coronavirus diseases (COVID-19) in China. Chin J Epidemiol. 2020; 41(2):145-151 (in Chinese).

24. Center for Disease Control and Prevention. Coronavirus Disease 2019 (COVID-19). https://www.cdc.gov/coronavirus/2019-nCoV/ summary.html?CDC_AA_refVal=https $\% 3 \mathrm{~A} \% 2 \mathrm{~F} \% 2 \mathrm{Fwww}$. cdc.gov\% 2Fcoronavirus\%2F2019-ncov\%2Fabout\%2Fwhat-you-should-do.html\# anchor_1580064337377. Accessed 20.02.17.

25. World Health Organization. Coronavirus disease (COVID-19) advice for the public. https://www.who.int/emergencies/diseases/ novel-coronavirus-2019/advice-for-public. Accessed 20.02.17.

26. Taglioni F, Cartoux M, Dellagi K, et al. The influenza A (H1N1) pandemic in Reunion Island: knowledge, perceived risk and precautionary behaviour. BMC Infect Dis. 2013;13:34.

27. de Zwart O, Veldhuijzen IK, Richardus JH, Brug J. Monitoring of risk perceptions and correlates of precautionary behaviour related to 
human avian influenza during 2006-2007 in the Netherlands: results of seven consecutive surveys. BMC Infect Dis. 2010;10:114.

28. Lau JT, Kim JH, Tsui HY, Griffiths S. Anticipated and current preventive behaviors in response to an anticipated human-to-human H5N1 epidemic in the Hong Kong Chinese general population. BMC Infect Dis. 2007;7:18.

29. Chowell G, Abdirizak F, Lee S, et al. Transmission characteristics of MERS and SARS in the healthcare setting: a comparative study. BMC Med. 2015;13:210.

30. Lee AM, Wong JG, McAlonan GM, et al. Stress and psychological distress among SARS survivors 1 year after the outbreak. Can J Psychiatry. 2007;52(4):233-240.

31. Cooksley WG. What did we learn from the Shanghai hepatitis A epidemic. J Viral Hepat. 2000;7(Suppl 1):1-3.

32. Lau JT, Kim JH, Tsui H, Griffiths S. Perceptions related to human avian influenza and their associations with anticipated psychological and behavioral responses at the onset of outbreak in the Hong Kong Chinese general population. Am J Infect Control. 2007;35(1):38-49.

33. Bener A, Al-Khal A. Knowledge, attitude and practice towards SARS. J R Soc Promot Health. 2004;124(4):167-170.

34. Baidu index. Research on the trend by the key word "psychological counseling". http://index.baidu.com/v2/main/index.html\#/trend/\% $\mathrm{E} 5 \% \mathrm{BF} \% 83 \% \mathrm{E} 7 \% 90 \% 86 \% \mathrm{E} 7 \% 96 \% 8 \mathrm{~F} \% \mathrm{E} 5 \% \mathrm{AF} \% \mathrm{BC}$ ?words=\%E5\% BF\%83\%E7\%90\%86\%E7\%96\%8F\%E5\%AF\%BC. Accessed 20.02.07 (in Chinese). 